\title{
Study on the Influence of fly ash, mineral powder and silicon powder on the performance of high-performance concrete
}

\author{
YANG Hua-quan $^{1}$, LIU Xue-ying ${ }^{1 *}$, and CHEN Xiao-dong ${ }^{2}$ \\ ${ }^{1}$ Zhejiang University of Water Resources and Electric Power, 310018 Hangzhou, Zhejiang, China \\ ${ }^{2}$ Zhejiang Institute of Water Resources and Ocean Engineering, 310018 Hangzhou, Zhejiang,China
}

\begin{abstract}
To study the effect of fly ash, mineral powder, and silica fume on the working performance and mechanical properties of $\mathrm{C} 70$ high-performance concrete by adding the same amount of fly ash, granulated blast furnace slag powder, and silica fume as a composite admixture to replace the amount of cement. Influencing the law, at the same time, the optimal dosage ratio of various admixtures is determined through the orthogonal experiment. The results show that: when adding $6 \%$ silica fume, it can improve the performance of high-performance concrete. When the amount is increased, the viscosity of the concrete increases and the fluidity decreases. Incorporating an appropriate amount of silica fume can greatly increase the compressive strength of concrete. When blended with fly ash in the proportion of $20 \%$, the performance of high-performance concrete is better. When the same amount of fly ash replaces cement, fly ash reduces hydration and improves the cohesion of concrete, $7 \mathrm{~d}, 28 \mathrm{~d}$ the compressive strength of the cube increases significantly. Adding 10\% mineral powder, mineral powder can affect the early compressive strength of highperformance concrete, extend the setting time of concrete, and improve the pumping capacity of concrete.
\end{abstract}

\section{Introduction}

High-Performance Concrete (abbreviated: HPC) is a new concept of concrete proposed by some developed countries based on the durability design of concrete structures in the late 1980s and early 1990s. It is also a new type of high-tech concrete. The concrete made with modern concrete technology is used on the basis of improving the performance of ordinary concrete. Since it was put forward for more than 20 years, countries around the world have carried out a lot of research, development, and popularization and application of it. Highperformance concrete has good working performance, high strength and high durability. Adding fly ash, granulated blast furnace slag powder, and silica fume can replace cement. The combined use of admixtures can refine the pore structure of concrete, improve compactness, and improve the performance of high-performance concrete. At the same time, it can reduce the amount of cement and concrete, reduce the energy consumption and material consumption of production and transportation, and reduce the damage to the environment. It not only uses resources rationally, optimizes economic benefits, but also well for environment ${ }^{[1]}[2]$.

In order to study the influence of different admixtures and admixtures in different proportions on the performance and compressive strength of high- performance concrete, this paper uses low water-binder ratio, high-efficiency polycarboxylic acid water-reducing agent and mineral admixtures take $\mathrm{C} 70$ high-performance concrete as an example ${ }^{[8]}$. By orthogonal test method, different dosages of fly ash, slag powder and silica fume are mixed respectively, and the dosage combination is tested to determine the optimal dosage of various admixture at the same time, analyze its influence on the working performance of high-performance concrete and the compressive strength of the cube.

\section{Test method and mix ratio}

According to the "Technical Regulations for High Strength Concrete Application" (JGJ/T281-2012) and the full calculation method of concrete mix proposed by Professor Chen Jiankui and Professor Wang Dongmin, we can calculate C70 high-performance concrete with a water-binder ratio of 0.3 and a sand ratio of $40 \% .{ }^{[1]}$ The design value of the mix ratio ${ }^{[3]}$, and conduct trial mixing to determine the amount of various materials. On the basis of trial mixing, keeping the total amount of cement material-unchanged, determine the mixing amount of the three admixtures by orthogonal experiment. Choose fly ash content of $10 \%, 20 \%$, mineral powder content of $10 \%$, $20 \%$, and silicon powder content of $6 \%, 8 \%$. The material consumption of the test concrete is shown in Table 1.

Table 1. Concrete material consumption

\begin{tabular}{|c|c|c|c|c|c|c|c|c|}
\hline Num & $\begin{array}{c}C \\
/ \mathrm{kg}\end{array}$ & $F-A / \mathrm{kg}$ & $M-P / \mathrm{kg}$ & $S-F / \mathrm{kg}$ & $W / \mathrm{kg}$ & $S / \mathrm{kg}$ & $\begin{array}{c}G \\
/ \mathrm{kg}\end{array}$ & $W R / \mathrm{kg}$ \\
\hline
\end{tabular}




\begin{tabular}{|c|c|c|c|c|c|c|c|c|}
\hline 1 & 389.98 & 52.7 & 52.7 & 31.6 & 158 & 706 & 1059 & 7.9 \\
\hline 2 & 379.44 & 52.7 & 52.7 & 42. & 158 & 706 & 1059 & 7.9 \\
\hline 3 & 337.28 & 52.7 & 105.4 & 31.6 & 158 & 706 & 1059 & 7.9 \\
\hline 4 & 326.74 & 52.7 & 105.4 & 42.2 & 158 & 706 & 1059 & 7.9 \\
\hline 5 & 337.28 & 105.4 & 52.7 & 31.6 & 158 & 706 & 1059 & 7.9 \\
\hline 6 & 326.74 & 105.4 & 52.7 & 42.2 & 158 & 706 & 1059 & 7.9 \\
\hline 7 & 284.58 & 105.4 & 105.4 & 31.6 & 158 & 706 & 1059 & 7.9 \\
\hline 8 & 274.04 & 105.4 & 105.4 & 42.2 & 158 & 706 & 1059 & 7.9 \\
\hline
\end{tabular}

\section{Concrete working performance test method}

When using concrete slump and slump expansion to evaluate the workability of concrete, slump is the distance between the height of the slump cylinder and the highest point of concrete collapse, and the expansion is the maximum diameter of the concrete collapsed and expanded ${ }^{[3]}$. At the same time, it is necessary to observe the water retention and cohesion of concrete. The slump and expansion of concrete reflect the fluidity and consistency properties of the concrete mixture.

According to the "Standard for Test Methods for the Performance of Ordinary Concrete Mixtures" (GB/T50080-2016), the concrete mixture should be evenly loaded into the slump cylinder in three layers. Each layer of the mixture should be evenly inserted 25 times in a spiral shape from the edge to the central. After tamping, the height of each layer of concrete mixture sample is about one-third of the cylinder height. When the concrete no longer slump or the slump time reaches 30 s, measure the height difference between the cylinder height and the highest point of the concrete sample after the slump with a steel ruler as the slump value of the concrete mixture. When the concrete mixture no longer diffuses or the diffusion time reaches $50 \mathrm{~s}$, a steel ruler should be used to measure the maximum diameter of the expanded surface of the concrete mixture and the diameter in the vertical direction as the expansion degree of the concrete mixture. The effect of different admixtures on the performance of high-performance concrete is shown in Table 2.

Table 2.Test results of performance of high-performance concrete

\begin{tabular}{|c|c|c|c|c|c|}
\hline Num & $\begin{array}{c}\text { Slump } \\
\text { /mm }\end{array}$ & Expansion $/ \mathrm{mm}$ & $\begin{array}{c}\text { Slump / } \\
\text { Expansion }\end{array}$ & Cohesion & $\begin{array}{c}\text { Water } \\
\text { retention }\end{array}$ \\
\hline S1 & 190 & 480 & 0.39 & good & good \\
\hline S2 & 180 & 480 & 0.38 & good & good \\
\hline S3 & 185 & 530 & 0.35 & good & good \\
\hline S4 & 210 & 500 & 0.42 & good & good \\
\hline S5 & 230 & 580 & 0.40 & good & good \\
\hline S6 & 210 & 500 & 0.42 & good & good \\
\hline S7 & 205 & 520 & 0.39 & good & good \\
\hline S8 & 200 & 500 & 0.40 & good & good \\
\hline
\end{tabular}

Through the slump and expansion test of highperformance concrete mixture, it is known that concrete has good fluidity. The sample numbers from Table 2 are: S1 and S2, S5 and S6, S7 and S8, when the content of fly ash and mineral powder remains unchanged, the content of silicon powder increases from $6 \%$ to $8 \%$, and the slump and the degree of expansion decreases with the increase of silicon powder content. The particle size of silica fume is very small, and the specific surface area is large. The addition of silica fume in high-performance concrete can better fill the pores between cement, which is beneficial to prevent concrete bleeding and improve concrete cohesion and water retention ${ }^{[4]}$. When $6 \%$ silica fume is added, the fluidity of concrete is better. When excessive silica fume is added, the viscosity of concrete will increase, the fluidity of concrete will decrease rapidly, and the overall workability will decrease. Therefore, more water reduction is needed. Concrete achieves the required fluidity.

From the sample number in Table 2: S1 and S5, S2 and S6, it is known that when the content of mineral powder and silica fume is unchanged, the fly ash increases from $10 \%$ to $20 \%$, and the concrete slump and spread the increase in fly ash increased significantly. When $10 \%$ fly 
ash is mixed, the ratio of slump to expansion is $\leq 0.4$, and when $20 \%$ fly ash is mixed, the ratio of slump to expansion is $\geq 0.4$, which shows that when the amount of fly ash increases at the same time, the fluidity of the concrete mixture also increases. When the same amount of fly ash replaces cement, it can reduce hydration, play a role of lubrication, and improve the viscosity of concrete.

The sample numbers in Table 2 are: S1 and S3, S2 and S4, S6 and S8, when the content of fly ash and silica fume is unchanged, the slag powder increases from $10 \%$ to $20 \%$, and the slump and expansion the degree increases with the increase of mineral powder content, but the increase is not obvious. Incorporating an appropriate amount of mineral powder can improve the fluidity of concrete, but the main function of mineral powder is to prolong the solidification time of the cement material, improve the internal structure of the concrete, and improve the impermeable of the concrete.

\section{Test methods for concrete mechanical properties}

According to "Specifications for Design of Concrete Structures" (GB50010-2019) and "Standards for Test Methods of Physical and Mechanical Properties of Concrete" (GB/T50081-2019), the standard value of compressive strength of cubes refers to the production and maintenance according to standard methods. In this test, a cube specimen with a side length of $100 \mathrm{~mm}$ is used. According to the conversion formula $\mathrm{f}_{\mathrm{cu}, 150}=0.95 \mathrm{f}_{\mathrm{cu}, 100}$, the concrete specimen is cured to the specified age in the standard curing room, and the compressive strength of $3 \mathrm{~d}$, $7 \mathrm{~d}$, and $28 \mathrm{~d}$ is measured according to the standard method. The compressive strength results are shown in Table 3:

Table3. Compressive strength of high-performance concrete

\begin{tabular}{|c|c|c|c|}
\hline \multirow{2}{*}{ Number } & \multicolumn{3}{|c|}{ Compressive strength of concrete cube (MPa) } \\
\cline { 2 - 4 } & $3 \mathrm{~d}$ & $7 \mathrm{~d}$ & $28 \mathrm{~d}$ \\
\hline S1 & 40.3 & 62.9 & 71.3 \\
\hline S2 & 44.9 & 64.7 & 76.3 \\
\hline S3 & 44.1 & 66.1 & 78.4 \\
\hline S4 & 50.2 & 71.2 & 86.8 \\
\hline S5 & 51.3 & 80.2 & 89.7 \\
\hline S6 & 50.6 & 77.8 & 78.7 \\
\hline S7 & 48.3 & 69.8 & 76.6 \\
\hline S8 & 54.5 & 75.3 & 80.2 \\
\hline & & & \\
\hline
\end{tabular}

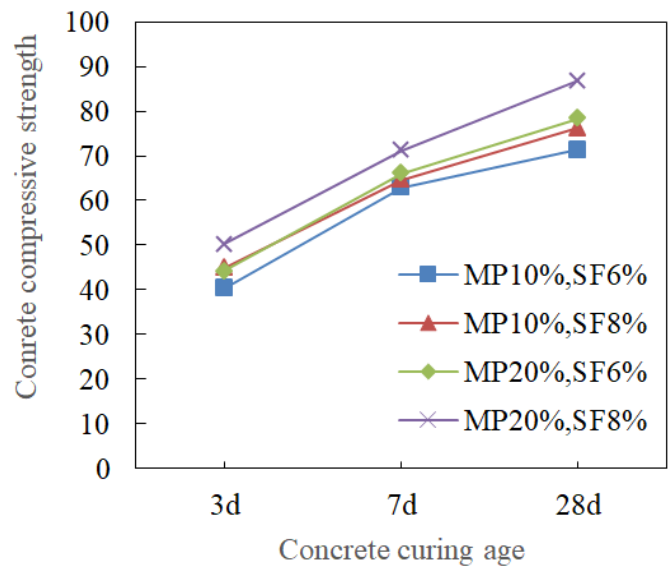

Fig1. The effect of mineral powder and silica fume at $10 \%$ fly ash

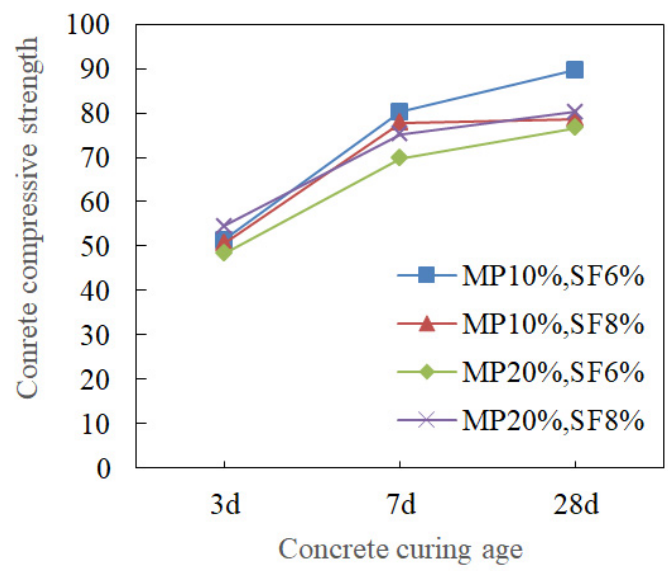

Fig2. The effect of mineral powder and silica fume at $20 \%$ fly ash

Result analysis: It can be seen from Figure 1 that when both fly ash and mineral powder are added at $10 \%$, with the increase of silica fume, the $3 \mathrm{~d}, 7 \mathrm{~d}$, and $28 \mathrm{~d}$ concrete compressive strengths all show an increasing trend. This is due to the large specific surface area of silica fume. After adding silica fume, the capillary water inside the concrete is constrained by the silica fume, which reduces the bleeding inside the concrete and improves the bonding force between the cement slurry and the aggregate, thereby making the concrete the compressive strength is increased. With the increase of mineral powder, the compressive strength growth rate of concrete in the middle and late stages is relatively fast, while the strength growth in the early stage is relatively slow. This is because the mineral powder contains more $\mathrm{SiO}_{2}, \mathrm{Al}_{2} \mathrm{O}_{3}$ and $\mathrm{Ca}(\mathrm{OH})_{2}$, which chemically react to form stable calcium silicate hydrate and calcium aluminum plastic hydrate, which helps concrete harden and increase strength ${ }^{[6]}$.

It can be seen from Figure 2 that when $20 \%$ fly ash and $10 \%$ mineral powder are mixed, with the increase of silica fume, the compressive strength of $3 \mathrm{~d}, 7 \mathrm{~d}$, and $28 \mathrm{~d}$ concrete will decrease slightly. The superimposition effect of the mixture increases the hydration effect, which reduces the fluidity of the concrete and reduces the overall work 
performance. With the increase of silica fume, the compressive strength of high-performance concrete first increases and then decreases. The early strength development is faster ${ }^{[5]}$. It can be seen from Figure 1 and Figure 2 that with the increase of fly ash, the late strength of high-performance concrete (after 7 days) increases faster, and the early compressive strength contrast is lower. Due to the increase of fly ash, the amount of cement decreases. The hydration rate of cement decreases, so the initial strength growth is slower, but as the age increases, fly ash reduces the heat generated by the internal hydration of the concrete, improves the density of the concrete, and reduces the porosity of the cement paste. The pore structure of the hardened body is improved, so the later strength of the high-performance concrete is greatly increased. [5] Since each component of different admixtures such as fly ash, mineral powder and silica fume has active molecules, under the action of the hydration reaction of cement, it promotes the hydration of different admixtures such as fly ash, mineral powder, silica fume, etc. So that different admixtures play their reactions at each age, thereby enhancing the strength of high-performance concrete at each age.

\section{Conclusions}

The compound mixing of fly ash, mineral powder and silica fume can make the high-performance concrete have better workability. Superimposed reaction of various admixtures, fly ash can improve the cohesion and plasticity of concrete. When $20 \%$ fly ash is added, the ratio of slump to expansion of high-performance concrete is greater than 0.4 , and the fluidity is the highest. Adding $6 \%$ silica fume, silica fume improves the workability of performance concrete. As the silica fume increases, the fluidity of the concrete decreases. The effect of mineral powder on the fluidity of concrete is not obvious. The main function of mineral powder is to extend the setting time of concrete and improve the pumping capacity. The three mixing of fly ash, mineral powder and silica fume can significantly improve the overall fluidity of highperformance concrete.

The content of fly ash, mineral powder and silica fume on the compressive strength of high-performance concrete varies with the content of the mixture. From the above test, it can be seen that when $20 \%$ fly ash, $10 \%$ slag powder, $6 \%$ silica fume are added to replace cement, the $28 \mathrm{~d}$ compressive strength of $\mathrm{C} 70$ high-performance concrete is the largest. The compressive strength in the early stage (before 7d) and the compressive strength of the late stage (after $7 d$ ) are significantly higher than other proportions. The amount of fly ash mixed with $20 \%$ instead of cement can improve the growth rate of the compressive strength of the high-performance concrete bigger.

The three-blending use of fly ash, mineral powder and silica fume is beneficial to improve the pores of the molecular particles of the cement material. The three mineral admixtures and cement form a good particle gradation, making the cement interior more dense and solid. The admixture has a volcanic effect, which is beneficial to improve the mechanical properties of high- performance concrete.

\section{References}

1. Wu Zhongwei. (1998). The development trend and problems of high-performance concrete (HPC). Building technology (01), 8-13.

2. Chen Lei, Xiao Jia, Tang Xianyan, Chen Feng , Liu Jing. (2007). Research on the effect of fly ash and slag on the performance of concrete. Comprehensive utilization of fly ash (02), 22-25.

3. Chen Jiankui, Wang Dongmin. (2000). A new method of high-performance concrete (HPC) mix design-full calculation method. Journal of The Chinese Ceramic Society (02), 194-198.

4. Li Qingfu, Xue Yanxin , Zhang Haiyang. (2012). Experimental study on the influence of different admixtures on the performance of high-performance concrete. Concrete (01), 58-61.

5. Xu Ke. (2013). Experimental study on the influence of different admixtures on the compressive strength of high-performance concrete. Highway Transportation Science and Technology (Applied Technology Edition) (08), 226-228.

6. Li Zhigang, Li Jiahe, Zhang Honggui. (2009). The influence of fly ash and slag composite admixture on the strength of concrete. Low temperature construction technology (04), 17-19.

7. Xiao Jia, Chen Lei, Zhao Jinhui. (2011). The influence of admixtures on the mechanical properties of C60 high-performance concrete. Low temperature building technology (04), 10-13.

8. Fu Baohua, Gai Dongfang \& Li Jun. (2016). The influence of the superposition effect of fly ash and mineral powder on the mechanical properties of highperformance concrete. Juye (07), 32-34.

9. Li Siqi, Meng Zhenya \& Zhang Shouzhi. (2013). The influence of fly ash and mineral powder on the permeability of high-performance concrete. Concrete (11), 119-121.

10. Zhang Haiyang, Guo Jun, Zhang Xuhui \& Li Weidong. (2014). The influence of fly ash and silica fume on the compressive strength of highperformance concrete. China and Foreign Highway (03), 312-316.

11. Tan Feng. (2017). C90 high-strength and highperformance concrete mix design and experimental research on its mechanical properties (Master's thesis, Chongqing Jiaotong University). 